\title{
PENGEMBANGAN COMPUTER ASSISTED INSTRUCTION MODEL TUTORIAL UNTUK MENINGKATKAN KEPEKAAN ANAK TERHADAP ALAM SEKITAR

\author{
Cecep Kustandi
} \\ e-mail: cecepkustandi@yahoo.com \\ Kurikulum \& Teknologi Pendidikan FIP Universitas Negeri Jakarta
}

\begin{abstract}
Abstrak: Penelitian ini bertujuan untuk mengembangkan Computer Assisted Instruction (CAI) Model Tutorial, dalam membentuk kepekaan siswa terhadap lingkungan sekitar pada pelajaran muatan lokal Pendidikan Lingkungan Hidup (mulok PLH) yang dikembangkan untuk memperbaiki sikap siswa terhadap lingkungan. Jika tujuan PLH ditekankan kepada perubahan sikap maka Computer Assisted Instruction (CAI) Model Tutorial berisi pembelajaran yang dapat ditempuh dengan menghadapkan siswa kepada permasalahan lingkungan yang ada. Setelah itu, dilanjutkan klarifikasi nilai, yaitu siswa diberikan kesempatan untuk menilai kondisi, membuat pilihan pemecahan dari alternatif yang tersedia dan menentukan langkah pemecahan masalah yang diperkuat dengan memperbanyak contoh oleh program CAI. Dengan demikian, penggunaannya diharapkan dapat menanggulangi masalah lingkungan, khususnya perubahan mendasar sikap siswa terhadap lingkungan sekitar. Penelitian ini menggunakan metode penelitian dan pengembangan dengan model evaluatif, dan eksperimental yaitu metode penelitian yang digunakan untuk menghasilkan produk tertentu dalam hal ini Computer Assisted Instruction (CAI).
\end{abstract}

Kata-kata kunci: Computer Assisted Instruction (CAI), model tutorial, pendidikan lingkungan hidup

\section{DEVELOPING COMPUTER ASSISTED INSTRUCTION TUTORIAL MODEL TO IMPROVE THE CHILDREN'S SENSITIVITY TO THE SURROUNDING ENVIRONMENT}

\begin{abstract}
This study aimed to develop a Computer Assisted Instruction (CAI) with tutorial model, in shaping students' sensitivity to the surrounding environment on the local content of Environmental Education which was developed to improve students' attitudes toward the environment. If the goal of EE is concerned with changes in the attitudes, the Computer Assisted Instruction (CAI) Model Tutorial contains learning that can be taken to expose students to environmental problems that exist, then proceed with value clarification, the students are given the opportunity to assess the conditions, make a choice of available solution alternatives and determine the trouble shooting steps that are reinforced by increasing the sample by the CAI program. Therefore, its use is expected to counter environmental issues, particularly fundamental change of students'attitudes toward the environment. This study used employed the research and development method with evaluative models, and experimental research method that is used to produce a particular product in this case Computer Assisted Instruction (CAI).
\end{abstract}

Keywords: Computer Assisted Instruction (CAI), tutorial model, Environmental Education

\section{PENDAHULUAN}

Kebijakan beberapa pemerintahan daerah menginstruksikan muatan lokal Pendidikan Lingkungan Hidup (mulok PLH) baik kota ataupun kabupaten di seluruh Indonesia merupakan terobosan yang tepat. Penerapan ini diharapkan akan menjadi percontohan bagi seluruh tingkatan sekolah di Indonesia. Penerapan mulok ini diharapkan dapat mengubah perilaku dan pola pandang masyarakat ke arah positif terkait persoalan lingkungan hidup. Tujuan utama program ini adalah mengenalkan dan menumbuhkan kecintaan akan lingkungan sejak dini. Alasan diadakannya program ini tidak terlepas dari berbagai masalah lingkungan hidup.

Berdasarkan tujuan di atas, tersirat bahwa masalah lingkungan hidup terutama berkaitan dengan manusia, bukan hanya lingkungan. Oleh karena itu, dalam pengembangan program PLH harus ditujukan pada aspek tingkah laku manusia, terutama interaksi manusia dengan lingkungan hidupnya dan kemampuan memecahkan masalah lingkungan. Selanjutnya, tujuan PLH harus sejalan dengan tujuan pendidikan secara umum. Hal penting lainnya adalah membantu manusia merealisasikan potensinya. Kegagalan PKLH yang lalu karena lembaga pendidikan formal terlalu 
menekankan kepada pencapaian individu untuk bersaing menjadi yang terbaik untuk mendapatkan penghargaan.

Dengan demikian, hal paling penting dalam menanggulangi masalah lingkungan adalah perubahan mendasar sikap manusia terhadap lingkungan. Jika tujuan PLH ditekankan kepada perubahan sikap, maka langkah pembelajaran yang dapat ditempuh adalah dengan menghadapkan siswa kepada permasalahan lingkungan yang ada. Setelah itu lanjutkan klarifikasi nilai, yaitu siswa diberikan kesempatan untuk menilai kondisi, membuat pilihan pemecahan dari alternatif yang tersedia dan menentukan langkah pemecahan. Sikap akan dapat terbentuk melalui cara tersebut dan diperkuat dengan memperbanyak contoh oleh guru (Harlen, 1992). Dalam proses pembelajarannya, PLH jangan dijadikan sebagai topik hapalan tetapi harus dikaitkan dengan dunia nyata yang dihadapinya sehari-hari (kontekstual) dan dunia nyata ini harus dijadikan objek kajian dalam konsep PLH.

Sejalan dengan permasalahan tersebut, di sisi lain teknologi informasi merupakan salah satu sub-sektor teknologi yang berkembang sangat pesat dan aplikasinya sangat luas dewasa ini. Hadirnya teknologi komputer berbasis multimedia berbentuk yang semakin banyak dipakai di segala bidang kehidupan terutama bidang pendidikan mulai pada tingkat dasar sampai perguruan tinggi sangat membantu pelaksanaan pendidikan. Namun komputer berbasis multimedia belum dimanfaatkan secara maksimal dalam proses belajar mengajar padahal komputer memiliki berbagai kemampuan yang dapat membantu guru dalam proses transfer ilmu pengetahuan diantaranya Computer Assisted Instruction (CAI).

Sejalan dengan pemaparan di atas yang menjadi fokus penelitian adalah mengembangkan teknologi komputer berbasis multimedia berbentuk Computer Assisted Instruction (CAI) Model Tutorial untuk meningkatkan kepekaan anak terhadap keberadaan alam sekitar melalui Pendidikan Lingkungan Hidup. Konten Computer Assisted Instruction (CAI) Model Tutorial yang dimaksud tersebut dikembangkan untuk memperbaiki sikap manusia terhadap lingkungan.

Jika tujuan PLH ditekankan kepada perubahan sikap maka Computer Assisted Instruction (CAI) Model Tutorial berisi pembelajaran yang dapat ditempuh adalah dengan menghadapkan siswa kepada permasalahan lingkungan yang ada. Setelah itu lanjutkan klarifikasi nilai, yaitu siswa diberikan kesempatan untuk menilai kondisi, membuat pilihan pemecahan dari alternatif yang tersedia dan menentukan langkah pemecahan. Sampai pada sikap akan dapat terbentuk melalui cara tersebut dan diperkuat dengan memperbanyak contoh oleh program.

Tujuan penelitian ini adalah mengembangkan media Computer Assisted Instruction (CAI) Model Tutorial dalam untuk meningkatkan kepekaan anak terhadap keberadaan alam sekitar melalui mulok Pendidikan Lingkungan Hidup untuk memperbaiki sikap manusia terhadap lingkungan.

\section{Kajian Teori}

\section{Pendidikan Lingkungan Hidup (PLH)}

PLH bertujuan meningkatkan pengetahuan, kesadaran, sikap, nilai dan perilaku lingkungan hidup yang bertanggung jawab. Perilaku dalam hal ini berhubungan langsung dengan niat untuk bertindak (intention to act). Namun sebelum sampai pada ketetapan bertindak, terdapat beberapa faktor yang mempengaruhi, yaitu (1) kesiapan dalam bertindak, (2) pengetahuan tentang strategi bertindak, (3) pengetahuan tentang isu, dan (4) faktor-faktor kepribadian seperti sikap, fokus kontrol, dan tanggung jawab individu (Danusaputro, 1981). Tugas guru dalam pembelajaran PLH adalah selain membentuk siswa untuk memiliki niat bertindak yang positif terhadap lingkungan hidup, juga memberikan kondisi yang mendukung ke arah perilaku yang sesuai dengan niat tadi. Hal ini disebabkan, untuk mencapai ke arah keberlanjutan lingkungan hidup.

Masalah lingkungan disebabkan karena ketidakmampuan mengembangkan sistem nilai sosial, gaya hidup yang tidak mampu membuat hidup kita selaras dengan lingkungan. Membangun gaya hidup dan sikap terhadap lingkungan agar hidup selaras dengan lingkungan bukan pekerjaan mudah dan bisa dilakukan dalam waktu singkat. Oleh karena itu, jalur pendidikan merupakan sarana yang tepat untuk membangun masyarakat yang menerapkan prinsip keberlanjutan dan etika lingkungan. Jalur pendidikan yang bisa ditempuh mulai dari tingkat Taman Kanakkanak sampai dengan Perguruan Tinggi.

PLH dapat diajarkan melalui berbagai cara seperti observasi, diskusi, kegiatan atau praktik lapangan, praktik laboratorium, laporan kerja praktik, seminar, debat, kerja proyek, magang dan kegiatan petualangan. Hal yang perlu diingat adalah jangan hanya ceramah tentang konsep sehingga siswa hanya mendengarkan dan pasif. Cara ini tidak akan bermakna tetapi sebaliknya siswa harus dilibatkan secara aktif mentalnya agar dapat mengonstruksi pengetahuan, pengalaman, dan keterampilannya yang pada gilirannya akan dapat diterapkan dalam kehidupan dan ditransfer kepada orang lain. Tempat yang dapat dijadikan objek kajian sangat bervariasi 
seperti lingkungan sekolah, lingkungan tempat tinggal, lingkungan perkotaan, pasar, terminal, selokan, sungai, sawah, taman kota, lapangan udara, pembangkit tenaga atom, danau, instalasi pengolahan air minum, pengolahan sampah, pipa buangan rumah tangga, tempat pembuangan sampah, dan lingkungan lain di sekitar atau dekat sekolah.

\section{Computer Assisted Instruction (CAI)}

Komputer adalah mesin yang dirancang khusus untuk memanipulasi informasi yang diberi kode, mesin elektronik yang otomatis melakukan pekerjaan, perhitungan sederhana, dan rumit (Arsyad, 2006:53). Menurut Hamalik (2005:236), komputer adalah suatu medium interaktif, dimana siswa memiliki kesempatan untuk berinteraksi dalam bentuk mempengaruhi atau mengubah urutan yang disajikan. Seperti halnya dengan penggunaan sumber-sumber audio visual yang dapat meningkatkan motivasi, menyajikan informasi dan prakarsa melalui stimulus visual dan audio, komputer mempunyai nilai lebih karena dapat memberi pengalaman kinestetik kepada siswa melalui penggunaan keyboard komputer. Dalam kaitan membantu pembelajaran siswa, komputer dapat dimanfaatkan sebagai media yang dapat digunakan guru dalam membantu pembelajaran di kelas. Potensi media komputer dapat dimanfaatkan untuk meningkatkan efektivitas proses pembelajaran.

Menurut Arsyad (2006:32) bahwa ciri media pembelajaran berbantuan komputer (CAI) adalah: (a) mereka dapat digunakan secara acak, nonsekuensial, atau secara linear; (b) mereka dapat digunakan berdasarkan keinginan siswa atau berdasarkan keinginan perancang/ pengembang sebagaimana direncanakannya; (c) biasanya gagasan-gagasan disajikan dalam gaya abstrak dengan kata, simbol, dan grafik; (d) prinsip-prinsip ilmu kognitif untuk mengembangkan media; serta (e) pembelajaran dapat berorientasi pada siswa dan melibatkan interaktivitas siswa yang tinggi. Dari uraian tentang pendapat-pendapat di atas dapat disimpulkan yang dimaksud dengan kegiatan pembelajaran berbantuan komputer adalah kegiatan pembelajaran yang menggunakan komputer secara langsung sebagai alat bantu dalam penyampaian isi kegiatan pembelajaran.

Selanjutnya Philips (1997:27) mengemukakan bahwa penggunakan komputer dalam kegiatan pembelajaran adalah:

"If multimedia interaktifnot suitet to transmission of information, which is better handled by books and lectures, then the question is raised, what is multimedia interaktif goodfor?"

(a) material which is hard to visualize such as microscopic

\section{processes}

(b) material which is three-dimensional which can't easily be conveyed wilh traditional two-dimentional media such as books and whiteboards.

(c) dynamic processes, where it is important to understand the relationships of moving objects.

(d) material which has a broad context, where a number of ideas need to be linked to from an understanding of the whole, not just the parts, and

(e) simulations of expensive, dangerous or complex processes, where understanding may be hindered by the mechanical details of perfoming the process, or where there is no possibility of using the real equipment.

Jadi dapat disimpulkan bahwa CAI dapat membuat peserta didik melatih kemampuan berpikir kritis dan kreatif dalam memecahkan suatu permasalahan secara individu maupun kelompok. Hal ini juga merupakan pendekatan "student-centered learning" yang membiarkan peserta didik mempunyai pola pikirnya sendiri dalarn mencapai tujuan belajarnya. Di satu sisi, peran guru juga berubah dari pemain utama menjadi pendamping dalam suatu pembelajaran.

Ada empat jenis format penyajian Computer Assisted Instruction (CAI) yaitu (1) latihan dan praktik, (2) tutorial, (3) simulasi, dan (4) pengajaran dengan instruksi komputer (Oemar Hamalik 2005:237). Menurut Arsyad (2006:158) bahwa dilihat dari situasi belajar dimana komputer digunakan untuk tujuan menyajikan isi pelajaran, CAI bisa berbentuk tutorial, drills and practices, simulasi dan games.

Dari beberapa pendapat di atas dapat disimpulkan bahwa format pembelajaran komputer adalah tutorial, drill and practice, simulasi, dan permainan dalam kegiatan pembelajaran.

\section{METODE PENELITIAN}

Tujuan dari penelitian pengembangan ini adalah untuk menghasilkan sebuah produk berupa program pembelajaran berbantuan komputer atau Computer Assisted Instruction (CAI) pelajaran Mulok Pendidikan Lingkungan Hidup untuk kelas V sekolah dasar dengan materi Bencana Alam. Selain itu, digunakan juga sebagai salah satu bahan ajar yang dapat dimanfaatkan di sekolah dasar.

Ahli media adalah orang yang menguasai mengenai media atau pakar media yang ingin dikembangkan dalam penelitian pengembangan kali ini. Adapun ahli media dalam penelitian kali ini adalah orang yang telah ahli dalam mengembangkan media pembelajaran berbantuan komputer atau Computer Assisted Instruction (CAI) yaitu Hendi Hendratman, MT Pakar Multimedia. 
Ahli materi adalah orang yang menguasai teori-teori mengenai materi yang bersangkutan dalam hal ini adalah materi mengenai bencana alam pada pembelajaran Mulok Pendidikan Lingkungan Hidup di jenjang sekolah dasar khususnya pada kelas V. Ahli materi yang terlibat pada penelitian ini adalah Yustia Suntari. M.Pd, seorang dosen jurusan PGSD UNJ.

Ahli desain pembelajaran adalah seorang yang menguasai mengenai desain pembelajaran. Ahli desain pembelajaran yang terlibat pada penelitian ini berasal dari lingkungan jurusan Kurikulum dan Teknologi Pendidikan Fakultas Ilmu Pendidikan, Cepi Riyana, M.Pd, seorang ahli media dari Universitas Pendidikan Indonesia Bandung, seorang dosen yang ahli dalam bidang evaluasi dan pembelajaran.

Pengguna pada penelitian kali ini adalah siswa kelas VSD yang mendapatkan materi mengenai struktur bumi. Dalam penelitian pengembangan kali ini pengguna yang akan menggunakan $\mathrm{CD}$ pembelajaran atau media Computer Assisted Instruction (CAI) ini adalah siswa kelas V SDN.

Penelitian untuk mengembangkan media Computer Assisted Instruction (CAI) dilakukan pada Sekolah Dasar Negeri Cibogo yang berkedudukan di Kecamatan Sukajadi, Bandung. Penelitian dimulai dari bulan April hingga November 2011

Instrumen yang digunakan dalam pengembangan Computer Assisted Instruction (CAI) ini berupa pertanyaan-pertanyaan mengenai kelengkapan yang terdapat pada Computer Assisted Instruction (CAI) yang akan diberikan kepada para responden, yaitu ahli materi, ahli media, dan pengguna yang diharapkan dapat melakukan evaluasi dan memberikan masukan terhadap Computer Assisted Instruction (CAI) ini.

Pengembangan expert judgement ini dilakukan berdasarkan acuan terhadap kesesuaian dan kelengkapan materi yang disajikan dengan kurikulum, kelengkapan pembelajaran, tata letak pada Computer Assisted Instruction (CAI) serta kelengkapan program yang terdapat pada Computer Assisted Instruction (CAI) yang dikembangkan.

Pada penelitian kali ini menggunakan dua jenis model pengembangan, yaitu model pengembangan instruksional (MPI) dan model pengembangan multimedia interaktif. Model pengembangan instruksional merupakan model utama yang digunakan dalam penelitian ini. Sedangkan model pengembangan multimedia interaktif diterapkan hanya pada saat tahapan mengembangkan bahan instruksional yang terdapat pada Model Pengembangan Instruksional yang terdiri dari: (a) mengidentifikasi kebutuhan instruksional dan menulis tujuan instruksional umum, (b) melakukan analisis instruksional, (c) mengidentifikasi perilaku dan karakteristik awal siswa, (d) merumuskan tujuan instruksional khusus, (e) menulis tes acuan patokan, (f) menyusun strategi instruksional, (g) mengembangkan bahan instruksional, dan (h) melaksanakan evaluasi formatif.

Model pengembangan multimedia interaktif (IMM) disisipkan pada tahapan keenam model pengembangan instruksional (MPI), yaitu pada saat mengembangkan bahan instruksional. Model IMM ini terdiri dari empat tahap pengembangan yaitu, design, development, evaluation, and implementation

Prosedur model pengembangan instruksional (MPI) terdiri dari delapan tahapan yang dilakukan secara rinci. Mulai dari mengidentifikasi kebutuhan instruksional dan menulis tujuan instruksional, melakukan analisis instruksional, mengidentifikasi perilaku dan karakteristik awal siswa, merumuskan tujuan instruksional khusus, mengembangkan tes acuan patokan, menyusun strategi instruksional, mengembangkan bahan instruksional, serta melakukan evaluasi formatif.

Pada tahapan mengembangkan bahan instruksional dilakukan berdasarkan model pengembangan multimedia interaktif yang terdiri dari empat tahapan yaitu design, development, evaluation dan implementation. a. Identifikasi kebutuhan instruksional dan menulis tujuan instruksional.

Pada tahapan ini adalah melakukan identifikasi atau merumuskan tujuan pembelajaran. Identifikasi kebutuhan instruksional dilakukan dengan observasi secara langsung serta mewawancarai wali kelas $\mathrm{V}$ serta beberapa siswa kelas V SD N Cibogo, sehingga memperoleh data mengenai kesenjangan yang terdapat pada pembelajaran Mulok Pendidikan Lingkungan Hidup (PLH). Kesenjangan tersebut merupakan jenis pengetahuan, keterampilan, serta sikap yang belum pernah dipelajari oleh siswa. Berikut merupakan kesenjangan yang diperoleh dari hasil wawancara: (a) siswa kurang memahami susunan yang terdapat di bumi melalui penjelasan yang diberikan oleh guru, (b) perolehan nilai ratarata siswa untuk mata pelajaran Mulok Pendidikan Lingkungan Hidup berada di bawah mata pelajaran wajib lainnya, dan (c) siswa kurang tertarik terhadap penjelasan materi yang ada sehingga kurang mampu mengendalikan diri di dalam kelas.

Berdasarkan identifikasi kebutuhan instruksional di atas, dapat dirumuskan tujuan pembelajaran secara umum. Adapun tujuan pembelajaran secara umum pada mata pelajaran Mulok Pendidikan Lingkungan Hidup kelas V dengan materi bencana 
alam yaitu siswa mampu menjelaskan dan mengidentifikasi bencana alam dan proses terjadinya bumi secara tepat.

b. Analisis instruksional

Berdasarkan analisis instruksional yang dilakukan terhadap materi yang akan diajarkan, dapat dirumuskan bahwa materi yang akan disajikan berbentuk prosedur yang berupa perpaduan berbagai materi yang memiliki tujuan sama namun tidak harus dilakukan secara berurutan.

Analisis instruksional menghasilkan perilaku-perilaku yang diharapkan dapat ditampilkan oleh siswa setelah melakukan proses pembelajaran. Perilaku tersebut adalah dengan mengidentifikasi kegiatan manusia yang dapat menimbulkan bencana di wilayah laut, pesisir, dan lautan

c. Identifikasi perilaku dan karakteristik awal siswa

Adapun perilaku awal yang harus dimiliki oleh siswa kelas V SD N Cibogo Kecamatan Sukajadi dalam proses pembelajaran Mulok Pendidikan Lingkungan Hidup dengan materi Bencana alam adalah telah memperoleh pelajaran Mulok Pendidikan Lingkungan Hidup pada kelas IV dan mengetahui sekitar 70\% dari pembelajaran Mulok Pendidikan Lingkungan Hidup (PLH) bencana alam secara umum

Sedangkan, karakteristik awal siswa SDN Cibogo adalah $60 \%$ siswa kelas $\mathrm{V}$ mampu mengoperasikan komputer. Selebihnya sebanyak $40 \%$ masih belum terbiasa menggunakan komputer yang dikarenakan keterbatasan teknologi yang tersedia dirumahnya masing-masing.

Siswa kelas V SDN Cibogo selalu ingin mengetahui mengenai hal baru. Tingkat antusiasme terhadap hal baru yang belum pernah mereka lihat sebelumnya sangat tinggi. Bahasa yang digunakan oleh siswa kelas V SD N Cibogo merupakan Bahasa Indonesia, hanya sekitar $10 \%$ dari keseluruhan jumlah siswa yang menggunakan bahasa daerah/logat bahasa daerah.

d. Merumuskan tujuan instruksional khusus

Tujuan instruksional khusus disusun berdasarkan tujuan umum yang telah dikembangkan sebelumnya. Tujuan instruksional khusus disusun berdasarkan istilah ABCD (audience, behavior, condition dan degree). Akan tetapi pada penjabaran tujuan instruksional khusus susunan kata berstruktur CABD (condition, audience, behavior dan degree). Berikut ini merupakan tujuan instruksional khusus yang disusun dengan istilah CABD.

1. Dengan menggunakan media Computer Assisted Instruction (CAI) dalam pembelajaran Mulok Pendidikan Lingkungan Hidup materi Bencana Alam pada proses pembelajaran, siswa akan dapat menjelaskan proses terjadinya bumi dengan tepat dan sesuai.

2. Dengan menggunakan media Computer Assisted Instruction (CAI) dalam pembelajaran Mulok Pendidikan Lingkungan Hidup materi struktur bumi, siswa akan dapat mengidentifikasikan lapisanlapisan atmosfer yang terdapat pada tata surya dengan tingkat pencapaian minmal $70 \%$.

3. Dengan menggunakan media Computer Assisted Instruction (CAI) dalam pembelajaran Mulok Pendidikan Lingkungan Hidup materi stuktur bumi, siswa akan dapat mengidentifikasikan lapisanlapisan penyusun bumi dengan benar hasil pencapaian siswa minimal $70 \%$ dari pengeluaran.

e. Mengembangkan tes acuan patokan

Tes acuan patokan yang dikembangkan berupa pertanyaan pilihan ganda sebanyak 15 butir yang diberikan pada akhir penjelasan materi bencana alam yang terdapat pada akhir program Computer Assisted Instruction (CAI). Dengan harapan penguasaan materi bencana alam oleh siswa meningkat. Butir pertanyaan berada pada rentang tingkat kognitif C1 hingga C3 yaitu mengingat, memahami, serta menerapkan.

f. Menyusun strategi instruksional

Strategi instruksional yang disusun berdasarkan tujuan instruksional yaitu siswa mampu menjelaskan dan mengidentifikasi bencana alam dan proses terjadinya bumi secara tepat. Metode yang akan digunakan dalam pembelajaran ini adalah Computer Assisted Instruction (CAI) atau pembelajaran berbantuan komputer.

g. Mengembangkan bahan instruksional

Sesuai dengan strategi pembelajaran yang telah dirancang, pada proses pembelajaran akan menggunakan sebuah bahan ajar baru yang sengaja didesain khusus untuk materi pesawat sederhana. Pada tahapan pengembangan bahan instruksional ini menggunakan model pengembangan yang dikemukakan oleh Rob Phillip yaitu multimedia interaktif. Pada model pengembangan ini dibagi menjadi empat tahapan, yaitu:

a. Design (desain)

Tahap awal dari model IMM ini adalah menentukan cakupan materi yang akan dikembangkan menjadi media Computer Assisted Instruction (CAI). Cakupan materi diperoleh berdasarkan analisis instruksional yang telah dibuat.

Tahapan selanjutnya adalah mengembangkan GBIM atau Garis Besar ISI Program yang berisikan mengenai penjelasan materi, flowchart serta storyboard. Flowchart berisikan mengenai struktur materi yang akan diproduksi. Storyboard merupakan rancangan 
pengembangan media Computer Assisted Instruction (CAI) yang berisikan materi yang telah disesuaikan untuk ditampilkan dalam tampilan.

Selanjutnya, membuat template atau layout yang akan digunakan sebagai tempat untuk menampilkan tampilan progam Computer Assisted Instruction (CAI). Pemilihan template berdasarkan kesesuaian dengan materi yang dikembangkan. Selain itu, tata letak antara gambar dengan tulisan yang terdapat pada template harus sesuai dan mudah dibaca oleh siswa.

\section{b. Development (pengembangan)}

Tahapan selanjutnya adalah mengembangkan storyboard menjadi sebuah program CAI. Dalam mengembangkan program diperlukan beberapa software penunjang seperti Adobe Flash CS4, Adobe Audition, Adobe Ilustrator CS 4, serta Adobe Photoshop CS 4. Ilustrasi yang digunakan khusus dikembangkan atau by design untuk program CAI ini. Pembuatan ilustrasi/gambar dilakukan menggunakan software Adobe Ilustrator ataupun Adobe Flash CS 4. Pembuatan animasi serta scripting dilakukan dengan menggunakan software Adobe Flash CS 4.

Video yang terdapat pada program CAI merupakan video by utilization yang diunduh dari website khusus yang berisikan mengenai video yaitu www. youtube.com. Penambahan video dimaksudkan agar siswa semakin memahami materi yang disampaikan melalui penyajian video.

Selanjutnya, tombol-tombol yang digunakan dalam program CAI merupakan tombol by utilization yang diperoleh dari aplikasi yang terdapat pada Adobe Flash CS 4 maupun dari internet. Tombol yang dipilih merupakan tombol yang sering digunakan pada sebuah program CAI. Hal ini ditujukan agar siswa mudah memahami tombol yang ada.

Hal terakhir yang perlu diperhatikan adalah pemilihan suara latar dan pembuatan suara narasi yang sesuai dengan storyboard yang telah dikembangkan. Pemilihan suara latar disesuaikan dengan layout dan materi yang dikembangkan. Pembuatan suara narasi dilakukan dengan menggunakan softwareAdobe Audition.

Setelah narasi selesai diproduksi, tahapan terakhir adalah pengintegrasian narasi, instrumen serta animasi sehingga menjadikan sebuah program CAI yang menarik dan interaktif.

c. Evaluation (evaluasi)

Evaluasi yang akan dilakukan pada tahap pengembangan produk adalah evaluasi formatif yang terdiri dari dua jenis evaluasi, yaitu evaluasi terhadap expert review dan pengguna. Setelah diperoleh hasil evaluasi expert review, produk CD pembelajaran di- revisi terlebih dahulu sesuai dengan masukan yang diberikan oleh para ahli. Sesudah direvisi, produk CAI akan diujicobakan kembali oleh pengguna melalui tiga tahapan, yaitu one to one evaluation, small group evaluation serta field test untuk mengetahui kekurang dari CAI yang telah diproduksi. Setelah diperoleh hasil evaluasi yang dilakukan oleh pengguna, maka dilakukan revisi terakhir sebelum produk CAI dapat digunakan dalam proses pembelajaran.

d. Implementation (implementasi)

Setelah melakukan tahap evaluasi yang panjang, maka produk Computer Assisted Instruction (CAI) yang telah selesai diproduksi diharapkan dapat digunakan oleh siswa kelas V SDN Cibogo dalam proses pembelajaran sesuai dengan tujuan pengembangan media pembelajaran Computer Assisted Instruction (CAI).

\section{g. Mengembangkan evaluasi formatif}

Seperti yang telah dijelaskan di atas, evaluasi formatif yang dikembangkan berupa expert jugdement yang berisikan beberapa butir pertanyaan mengenai kelengkapan yang ada pada Computer Assisted Instruction (CAI), seperti materi, tata letak, penggunaan gambar, unsur suara serta interaksi yang telah dikembangkan. Evaluasi ini juga diujikan kepada pengguna Computer Assisted Instruction (CAI) yaitu siswa kelas V SD N Cibogo. Adapun evaluasi formatif yang akan dilakukan terbagi menjadi beberapa tahap, yaitu:

a. Mengembangkan evaluasi formatif

Evaluasi formatif yang dikembangkan berupa expert judgement yang berisikan beberapa butir pertanyaan mengenai kelengkapan yang ada pada Computer Assisted Instruction (CAI), seperti materi, tata letak, penggunaan gambar, unsur suara serta interaksi yang telah dikembangkan. Evaluasi ini diujikan kepada pengguna Computer Assisted Instruction (CAI) yaitu siswa kelas V SD N Cibogo. Adapun evaluasi formatif yang akan dilakukan terbagi menjadi beberapa tahap.

Pertama, evaluasi perorangan atau one to one evaluation yang dilakukan secara langsung kepada satu atau tiga orang calon pengguna dengan menggunakan instrumen kuesioner untuk memperoleh masukan mengenai kelengkapan yang ada pada program CAI yang nantinya sebagai bahan pertimbangan untuk melalukan revisi terhadap program CAI. Pemilihan calon pengguna dilakukan dengan memilih sesuai dengan populasi sasaran yaitu pengguna yang memiliki kemampuan sedang, di atas sedang, dan di bawah sedang.

Kedua, evaluasi kelompok atau small group evaluation yang dilakukan terhadap kelompok kecil calon pengguna program Computer Assisted Instruction (CAI) 
yang berjumlah 8 hingga 12 orang yang bertujuan untuk memperoleh masukan terhadap program Computer Assisted Instruction (CAI). Pemilihan calon pengguna yang akan mengikuti proses evaluasi ini juga dilihat dari populasi sasaran, yaitu pengguna berkemampuan sedang, di atas sedang, dan di bawah sedang.

Ketiga, evaluasi lapangan atau field test adalah uji coba langsung terhadap program Computer Assisted Instruction (CAI) yang telah dikembangkan kepada sekelompok besar calon pengguna yang dilakukan sebelum program Computer Assisted Instruction (CAI) yang telah dikembangkan dapat digunakan pada proses pembelajaran sesungguhnya.

6. Teknik Evaluasi

Evaluasi yang dilakukan dalam pengembangan Computer Assisted Instruction (CAI) ini terbagi menjadi dua tahap, yaitu expert review serta evaluasi yang dilakukan terhadap calon pengguna.

Expert review dilakukan sebanyak 3 kali, yaitu yang dilakukan terhadap seorang ahli materi, ahli media serta seorang ahli desain pembelajaran.

Evaluasi dilakukan dengan menggunakan instrumen penilaian dan teknik wawancara langsung terhadap expert review dengan tujuan agar masukan yang diberikan akan lebih mudah dipahami. Evaluasi yang kedua yaitu dilakukan terhadap calon pengguna program Computer Assisted Instruction (CAI) yang dalam hal ini adalah siswa kelas V SDN Cibogo. Evaluasi dilakukan sebanyak tiga kali yaitu, "one to one evaluation, small group evaluation dan field test evaluation". One to one evaluation dilakukan dengan melibatkan satu atau tiga orang siswa yang dipilih dengan mewakilkan tiap-tiap jenjang kemampuan intelegensi siswa yaitu siswa yang berinteligensi sedang, tinggi dan rendah dengan menggunaan teknik evaluasi wawancara.

Small group evaluation dilakukan terhadap sekelompok siswa yang berjumlah 9 hingga 12 orang yang dipilih mewakili tiap jenjang inteligensi siswa. Evaluasi ini menggunakan instrumen kuesioner untuk memperoleh masukan yang dapat digunakan untuk merevisi program Computer Assisted Instruction (CAI). Field test atau evaluasi lapangan adalah evaluasi yang terakhir dilakukan dengan melibatkan seluruh calon pengguna program Computer Assisted Instruction (CAI) atau siswa kelas V SD Cibogo. Evaluasi yang dilakukan menggunakan instrumen kuesioner untuk mengetahui tingkat kepuasan menggunakan program Computer Assisted Instruction (CAI). Hasil dari tiap evaluasi yang dilakukan, digunakan untuk meningkatkan kualitas dari program Computer Assisted Instruction (CAI) yang telah dikembangkan.

\section{HASIL DAN PEMBAHASAN}

\section{Nama Produk}

Produk yang dihasilkan pada penelitian ini adalah Computer Assisted Instruction (CAI) yang dikemas dalam bentuk compact disc (CD) yang dapat dimanfaatkan pada pembelajaran Mulok Pendidikan Lingkungan Hidup kelas V Sekolah Dasar (SD), yang terdiri dari tampilan gambar, animasi, teks dan suara yang diintegrasikan menjadi satu kesatuan bahan ajar.

\section{Karakteristik Produk}

a. Spesfikasi Sistem

Penggunaan media Computer Assisted Instruction (CAI) memerlukan bantuan komputer yang memiliki spesifikasi tersendiri. Spesifikasi komputer yang dapat digunakan untuk menjalankan produk multimedia interaktif untuk kelas V SD ini sebagai berikut:

(1) Processor Pentium III.

(2) Memori/RAM yang digunakan minimal berukuran 512 MB dengan Hardisk minimal 80 GB.

(3) Sistem Operasi yang dapat menjalankan produk ini adalah Windows XP, Windows Vista, Windows 7, Machintos 9, Machintos X, Machintos Tiger, Unix, Linux, AIX, HPA/UX, dan Solaris.

(4) Monitor yang dapat digunakan untuk menampilkan produk adalah monitor tabung (CRT) dan juga monitor LCD (Liquid Crystal Display).

(5) CD-ROM/DVD ROM Drive, Mouse, Keyboard, Speaker/Headset

\section{Kelebihan Produk}

Setelah melakukan uji coba terakhir terhadap calon pengguna dapat disimpulkan bahwa produk yang dikembangkan memiliki kelebihan sebagai berikut: (a) produk dapat digunakan untuk pembelajaran mandiri maupun pembelajaran di dalam kelas yang diproyeksikan dengan menggunakan proyektor, (b) produk mudah digunakan oleh pengguna, (c) produk dikemas dengan tampilan yang menarik dan terdapat soal tes serta permainan didalamnya, dan (d) tidak membutuhkan banyak software aplikasi komputer untuk menggunakan produk ini

\section{Prosedur Pemanfaatan}

Berikut ini adalah prosedur yang dilakukan untuk menggunakan/memanfaatkan produk ini pada proses pembelajaran: (a) pastikan komputer yang akan digunakan dalam keadaan hidup dan telah tersambung dengan speaker atau headset, (b) masukkan CD Pembelajaran "Multimedia Interaktif PLH untuk Kelas V SD" ke dalam CD-ROM atau DVD-ROM. (c) program akan running secara otomatis jika menggunakan windows Vista, XP dan dibawahnya, (d) sedangkan untuk windows 7 Klik ganda pada file "PLH.exe", 
(e) Computer Assisted Instruction (CAI)sudah dapat digunakan

Untuk memudahkan pengguna Computer Assisted Instruction (CAI), telah dibuatkan navigasi/ petunjuk penggunaan.

\section{Hasil Uji Coba}

Produk yang dikembangkan dalam penelitian ini tidak serta merta sempurna, akan tetapi melalui berbagai tahapan uji coba. Uji coba dilakukan sebanyak dua kali, yaitu uji coba produk oleh expert review serta uji coba produk kepada calon pengguna dalam tabel 1.

Tabel 1. Hasil Uji Coba

Computer Assisted Instruction (CAI)

\begin{tabular}{|c|c|c|c|}
\hline \multirow{3}{*}{$\begin{array}{l}\text { Uji coba } \\
\text { expert re- } \\
\text { view }\end{array}$} & $\begin{array}{l}\text { Uji coba terhadap ahli } \\
\text { materi }\end{array}$ & 3,3 & Sangat Baik \\
\hline & $\begin{array}{l}\text { Uji coba terhadap ahli } \\
\text { media }\end{array}$ & 2,9 & Baik \\
\hline & $\begin{array}{l}\text { Uji coba ahli desain pem- } \\
\text { belajaran }\end{array}$ & 2,9 & Baik \\
\hline \multirow{3}{*}{$\begin{array}{l}\text { Uji coba } \\
\text { penggu- } \\
\text { na }\end{array}$} & $\begin{array}{l}\text { Uji coba perorangan (one } \\
\text { to one evaluation) }\end{array}$ & 3 & baik \\
\hline & $\begin{array}{l}\text { Uji coba kelompok kecil } \\
\text { (small group evaluation) }\end{array}$ & 3.3 & Sangat Baik \\
\hline & $\begin{array}{l}\text { Uji coba tes lapangan (field } \\
\text { test evaluation) }\end{array}$ & 3.3 & Sangat Baik \\
\hline
\end{tabular}

Tabel 2. Pernyataan Hasil Uji Coba

Computer Assisted Instruction (CAI)

\begin{tabular}{|c|c|c|c|}
\hline $\begin{array}{l}\text { Pernyataan } \\
\text { mengenai } \\
\text { kemudahan } \\
\text { produk CAI } \\
\text { untuk digu- } \\
\text { nakan }\end{array}$ & 3,1 & $\begin{array}{c}\text { sangat } \\
\text { baik }\end{array}$ & $\begin{array}{l}\text { Hal ini sesuai dengan pendapat } \\
\text { Smaldino yang mengatakan bahwa } \\
\text { CAI melibatkan siswa untuk bebas } \\
\text { berpindah materi, sehingga siswa } \\
\text { terlibat secara aktif dalam proses } \\
\text { pembelajaran. Dalam konteks ini, } \\
\text { media CAI harus mudah digunakan } \\
\text { oleh siswa agar dapat berpartisipasi } \\
\text { aktif dalam pembelajaran. } \\
\text { (Smaldino, 2008:172) }\end{array}$ \\
\hline $\begin{array}{l}\text { Pernyataan } \\
\text { mengenai pen- } \\
\text { yajian media } \\
\text { CAI menarik- } \\
\text { membangkit- } \\
\text { kan motivasi } \\
\text { belajar siswa } \\
\text { dan kemu- } \\
\text { dahan materi } \\
\text { untuk dipahami } \\
\text { serta media } \\
\text { pembelajaran }\end{array}$ & 3,3 & $\begin{array}{c}\text { sangat } \\
\text { baik }\end{array}$ & $\begin{array}{l}\text { Menurut Smaldino, penyajian } \\
\text { media (CAI) harus dibuat } \\
\text { semenarik mungkin dikarenakan } \\
\text { media CAI terdiri atas berbagai } \\
\text { informasi yang disajikan dalam } \\
\text { berbagai bentuk sehingga } \\
\text { pengelolaan berbagai informasi } \\
\text { harus diatur sedemikian rupa agar } \\
\text { penyajian media (CAI) menarik dan } \\
\text { membangkitkan motivasi belajar } \\
\text { siswa. (Smaldino, 2008:173) }\end{array}$ \\
\hline $\begin{array}{l}\text { Pernyataan } \\
\text { mengenai pen- } \\
\text { yajian ilustrasi } \\
\text { menarik serta } \\
\text { ilustrasi men- } \\
\text { jelaskan materi } \\
\text { pembelajaran }\end{array}$ & 3,3 & $\begin{array}{c}\text { sangat } \\
\text { baik }\end{array}$ & $\begin{array}{l}\text { Hal ini sejalan dengan pendapat } \\
\text { Smaldino yang mengatakan dalam } \\
\text { CAI terdapat suatu fitur atau efek } \\
\text { khusus yang dapat mendukung } \\
\text { materi pembelajaran maupun hanya } \\
\text { sebagai hiasan media yang hanya } \\
\text { menambah daya tarik tampilan } \\
\text { media (Smaldino, 2008:173) }\end{array}$ \\
\hline
\end{tabular}

\begin{tabular}{|l|c|c|l|}
\hline $\begin{array}{l}\text { Pernyataan } \\
\text { mengenai, } \\
\text { kesesuaian } \\
\text { penggunaan } \\
\text { huruf, huruf, } \\
\text { warna, suara, } \\
\text { serta tata letak } \\
\text { dalam tampilan } \\
\text { CAI }\end{array}$ & 2,8. & Baik & $\begin{array}{l}\text { Smaldino yang mengatakan bahwa } \\
\text { komponen tampilan huruf, warna, } \\
\text { suara, serta tata letak menjadi } \\
\text { bagian yang harus diperhatikan } \\
\text { dengan seksama agar kom- } \\
\text { ponen-komponen tersebut tidak } \\
\text { menjadi hambatan kognitif dalam } \\
\text { mengungkapkan makna yang ter- } \\
\text { dapat dalam media yang disajikan } \\
\text { (Smaldino, 2008:174) }\end{array}$ \\
\hline $\begin{array}{l}\text { Pernyataan } \\
\text { mengenai } \\
\text { kejelasan } \\
\text { navigasi }\end{array}$ & 3,3 & $\begin{array}{l}\text { Sangat } \\
\text { baik. }\end{array}$ & $\begin{array}{l}\text { Petunjuk penggunaan media CAI } \\
\text { harus dibuat sejelas mungkin } \\
\text { karena sesuai dengan kelebihan } \\
\text { media CAI yang dikemukakan oleh } \\
\text { Smaldino media CAI merupakan } \\
\text { media pembelajaran yang bersifat } \\
\text { individu sehingga petunjuk peng- } \\
\text { gunaan perlu dibuat secara jelas } \\
\text { (Smaldino, 2008:174) }\end{array}$ \\
\hline $\begin{array}{l}\text { Sernyataan } \\
\text { kesesuaian } \\
\text { waktu } \\
\text { penyajian }\end{array}$ & 3,3 & $\begin{array}{l}\text { Smaldino mengatakan bahwa } \\
\text { dalam pembelajaran menggunakan } \\
\text { multimedia (media CAI) harus } \\
\text { mempersiapkan penyajian materi } \\
\text { sebaik mungkin agar siswa dapat } \\
\text { memperoleh pengalaman belajar } \\
\text { yang baik. Oleh karena itu, waktu } \\
\text { penyajian dari media CAI harus } \\
\text { diatur sebaik mungkin (Smaldino, } \\
\text { 2008:174) }\end{array}$ \\
\hline
\end{tabular}

Sehingga secara keseluruhan, hasil dari penilaian yang dilakukan pada tahapan field test menghasilkan penilaian bahwa media CAI yang dikembangkan masuk dalam kategori baik dengan perolehan nilai rata-rata dari keseluruhan pernyataan adalah 3 .

Pada tahapan field test, pemberian posttest ataupun test akhir juga dilakukan setelah calon pengguna mengisi instrument penilaian. Pemberian posttest ditujukan untuk menilai efektifitas media CAI terhadap pembelajaran. Soal posttest berbentuk pilihan ganda yang berjumlah sebanyak 30 butir soal.

Dari keseluruhan nilai perolehan posttest calon pengguna, diperoleh nilai rata-rata sebesar 8 dan masuk ke dalam kriteria baik.

\section{PENUTUP}

\section{Kesimpulan}

Berdasarkan pengembangan dan hasil uji coba yang telah dilakukan ke beberapa responden baik terhadap ahli media, ahli materi terakhir terhadap ahli desain pembelajaran media Computer Assisted Instruction(CAI) rata-rata dikatakan baik untuk digunakan dalam pembelajaran Pendidikan Lingkungan Hidup (PLH). Begitu juga uji coba terhadap calon pengguna, melalui one to one evaluation, small group evaluation, dan terakhir adalah field test evaluation yang dilaksanakan terhadap seluruh calon pengguna masuk ke dalam kategori baik. 


\section{Implikasi}

Produk yang dikembangkan tentunya memiliki impikasi terhadap proses pembelajaran Mulok Pendidikan Lingkungan Hidup (PLH) yaitu dapat digunakan sebagai media pembelajaran, sehingga kejenuhan siswa terhadap proses pembelajaran yang dilakukan di sekolah dapat teratasi. Selain itu, implikasi produk terhadap jurusan Teknologi Pendidikan adalah sebagai salah satu referensi dari penelitian pengembangan media Computer Assisted Instruction (CAI) model tutorial dengan harapan penelitian mengenai pengembangan media Computer Assisted Instruction (CAI) akan semakin baik dan berkembang pada masa yang akan datang.

\section{Saran}

Berdasarkan hasil penelitian, ada beberapa saran yang dapat dilakukan berkenaan dengan pengembangan CAI yaitu mata pelajaran lain dan materi lain dari PLH diharapkan dapat mengembangkan media ini, sosialisasi terhadap produk ini juga diperlukan dengan harapan dapat membantu peran guru dalam proses pembelajaran sehingga dapat dikembangkan lebih baik, kreatif, dan inovatif; serta diseminasi terhadap produk ini perlu dilakukan untuk memperkenalkan produk ke sekolah-sekolah.

\section{DAFTAR PUSTAKA}

Arsyad, A. (2006). Media pembelajaran. Jakarta. PT Radja Grafindo Perkasa

Danusaputro, St. M. (1981). Environmental education and training. Bandung: Binacipta Publishing Company

Hamalik, O. (1985). Media pembelajaran. Jakarta: Bumi Aksara

Harlen, W. (1992). The teaching of science. London: David Fulton Publisher.

Harlen, W. (1992). Primary science: Taking the plunge. USA: Heinemann Educational Books.

Phillips, R. (1997). The developer's handbooks to multimedia interaktif : A practice guide for educational applications. London: Kogan Page Limited.

Smaldino, H.,\& Moelenda, R. (2008). Instructional media anf technologies for learning. New Jersey: Merril an Imprint of Prentice Hall Englewood Cliff. 